\title{
Nexus between residential electricity consumption and household characteristics: heterogeneous urban and rural panel evidences from North China
}

\author{
Mingliang Liang ${ }^{1}$, Wenxuan $\mathrm{Li}^{1}$, Jie $\mathrm{Ji}^{1}$, Lili $\mathrm{Liu}^{2}$, Shiying Zhang ${ }^{2}$, Huiru Zhao ${ }^{2}$, and Sen $\mathrm{Guo}^{2, *}$ \\ ${ }^{1}$ North China Branch of State Grid Corporation of China, Beijing 100053, China \\ ${ }^{2}$ School of Economics and Management, North China Electric Power University, Beijing 102206, China
}

\begin{abstract}
With the growth of residential electricity consumption and the development of power energy conservation, exploring the factors that affect residential electricity consumption is of great significance for promoting the sustainable development of the regional economy-power system. This paper examines the influencing factors of residential electricity consumption according to the data in 6 provinces in North China over 2008-2018, and two panels named urban panel and rural panel are constructed. Three conventional influencing factors are selected in this paper, namely, population (POP), per capita disposable income (DI) and per capita consumption expenditure (PCCE). Furthermore, considering that household characteristics have an impact on residential electricity consumption, this paper adds the number of household appliances (HA) and the per capita housing area (LS) into the factor set. Heterogeneous panel analysis techniques are applied to achieve the analysis, finding that household characteristics have significant impacts on electricity consumption of urban and rural residents, and the impact on electricity consumption of urban residents is greater than that on rural residents. Based on the empirical results, this paper puts forward several policy recommendations to effectively improve the residential electricity consumption and reduce the gap between urban and rural residential electricity consumption.
\end{abstract}

\section{Introduction}

With the promotion of air pollution prevention and control policies, various regions in China have responded positively to national advocacy and gradually carried out the work of energy conservation and emission reduction [1]. Meanwhile, along with continuous development of economy and improvement of residents' living standards, the residential electricity consumption has become an important part of the electricity consumption of the whole society. Therefore, investigating the influence factors of residential electricity consumption can accurately grasp the characteristics of residential electricity consumption, so as to provide basis for grid planning and energy policy formulation [2], which is conducive to promoting the sustainable development of regional power and economy.

Residential electricity consumption is affected by many factors, like power price, climate characteristics, population size and people's living level [3]. Some scholars examined the impact of single factor on the electricity consumption of residents. For example, Zhang and Lin studied the relationship between electricity price and residential electricity consumption, and then found that electricity price was a key factor affecting residential electricity consumption [4]. Different scholars have adopted several methods to explore factors affecting residential electricity consumption, of which the econometric method is the most widely used [5]. Meanwhile, some scholars have adopted other methods to explore the factors affecting residential electricity consumption. Chen et al. developed a novel data-driven approach to examine the relationship between residential electricity consumption and household demographics and housing types [6].

In line with the above discussion, there are a series of effective methods for exploring the factors affecting residential electricity consumption, which can provide rich reference for the analysis in this paper, but there is still room for improvement. Based on this, this paper makes the following improvements:

(1) In order to more accurately grasp the influencing factors of residential electricity consumption, this paper divides residential electricity consumption into urban and rural residential electricity, and constructs two balanced panels for analysis accordingly. Furthermore, this paper introduces variables reflecting the characteristics of households, namely the number of household appliances and the per capita housing area, which expands the set of influencing factors for residential electricity consumption, and enhances comprehensiveness and pertinence of the research results.

(2) Considering the heterogeneity of the balanced panels constructed, this paper designs an econometric analysis framework based on heterogeneous panels,

*Corresponding author: guosen@ncepu.edu.cn 
including unit root test, panel cointegration test and heterogeneous panel estimation. Then, the interactions between residential electricity consumption and its influencing factors in urban and rural areas in North China are examined systematically and comprehensively.

\section{Materials and methods}

\subsection{Panel unit root test}

Before further empirical analysis, the unit root test is an essential step which can determine whether the variable is stable to avoid false regression. Normally, some panel unit root tests are widely used, like Breitung test, LLC test, IPS test and ADF test. However, all of these unit root tests are the first-generation unit root test, which is usually used when the cross-section is not correlated. When the panel has cross-sectional correlation, the first-generation unit root test usually over-rejects the null hypothesis. Therefore, Pesaran developed a panel root $t$ statistic to solve the cross-sectional correlation, as shown below:

$$
\Delta z_{i t}=\alpha_{i}+\beta_{i}^{*} z_{i, t-1}+c_{0} \bar{z}_{t-1}+c_{1} \Delta \bar{z}_{t}+\mu_{i t}
$$

Among them, $\bar{z}_{t}=N^{-1} \sum_{i=1}^{N} z_{i t}$ represents the difference operator. Taking into account the sequence correlation in the data, the extended model is as follows:

$$
\begin{gathered}
\Delta z_{i t}=\alpha_{i}+\beta_{i}^{*} z_{i, t-1}+c_{0} \bar{z}_{i-1}+\sum_{m=0}^{r} c_{m+1} \Delta \bar{z}_{t-m}+ \\
\sum_{n=1}^{r} d_{n} \Delta z_{i, t-n}+\mu_{i t}
\end{gathered}
$$

where $r$ is the lag order determined in the AIC and SIC criteria. For each section $r$, use the expanded CADF formula (2) to perform regression, and then get the $t$ statistic. On this basis, CIPS statistics consist of the following:

$$
\text { CIPS }=N^{-1} \sum_{i=1}^{N} C A D F_{i}
$$

\subsection{Panel co-integration test}

The above co-integrated variables of the same order that pass the unit root test, Pedroni proposed a panel cointegration test technique to test whether there is a longterm equilibrium relationship between variables. Using the following model:

$$
\begin{aligned}
\operatorname{LnE}_{i t}=\alpha_{i t} & +\beta_{i} t+\gamma_{1 i} \operatorname{LnPOP} P_{i t}+\gamma_{2 i} \operatorname{LnDI}_{i t} \\
& +\gamma_{3 i} \operatorname{LnPCC} E_{i t}+\gamma_{4 i} \operatorname{LnH}_{i t} \\
& +\gamma_{5 i} \operatorname{LnLS} S_{i t}+\varepsilon_{i t}
\end{aligned}
$$

where $\mathrm{i}$ and $\mathrm{t}$ represent the provinces and time respectively. $\alpha_{i t}$ and $\beta_{i t}$ are fixed effects and linear time trends in each province and city, respectively. $\varepsilon_{i t}$ is the estimated residual, which is the deviation from the longterm equilibrium. $\gamma_{1 i}, \gamma_{2 i}, \gamma_{3 i}, \gamma_{4 i}, \gamma_{5 i}$ are elastic coefficients relative to $\mathrm{POP}_{\text {it }}, \mathrm{DI}_{\text {it }}, \mathrm{PCCE}_{\text {it }}, \mathrm{HA}_{\text {it }}, \mathrm{LS}_{\text {it }}$ respectively. The stationarity of the residual of $\varepsilon_{\text {it }}$ represents the co-integration relationship between the analysis variables, and the unit root test is expressed as follows:

$$
\varepsilon_{i t}=\rho_{i} \varepsilon_{i, t-1}+v_{i t}
$$

where the null hypothesis is $H_{0}: \rho_{i}=1$.It means that $\varepsilon_{\text {it }}$ is non-stationary, and there is no cointegration relationship among the analyzed variables.

\subsection{Panel data model estimation}

Based on the co-integration variables tested above, the balance relationship between LnE, LnPOP, LnDI, LnPCCE, LnHA, and LnLS variables are estimated. Ordinary least squares estimator (OLS) has certain limitations. When the regression factor is not strictly exogenous, it will cause biased estimates of the long-term equation parameters. This has resulted in the dynamic least squares estimator (DOLS) and the fully modified least squares estimator (FMOLS) being proposed as alternative methods of panel co-integration estimation, which can correct the deviation caused by endogeneity and serial correlation in traditional OLS estimators.

The FMOLS estimation method eliminates the correlation between the explanatory variable and the random interference term, thereby obtaining the consistency of the co-integration parameter estimator, which is used to process the correction of the sequence correlation. DOLS adds the explanatory variable lag term to the co-integration equation to adjust the error parameters.

In the case of a small sample size, the deviation of the panel DOLS estimator is smaller than the panel OLS and FMOLS estimator, which has better sample properties.

\section{Results and discussion}

\subsection{Descriptive statistics of variables}

\begin{tabular}{|c|c|c|c|c|c|c|c|}
\hline & Variable & BJ & TJ & HB & SX & SD & IN \\
\hline Urban & $E$ & $7.5075 \%$ & $6.9802 \%$ & $7.3802 \%$ & $9.7220 \%$ & $8.5984 \%$ & $5.7480 \%$ \\
\hline \multirow[t]{5}{*}{ Panel } & POP & $2.3750 \%$ & $3.2923 \%$ & $0.7119 \%$ & $3.1844 \%$ & $2.9122 \%$ & $2.2193 \%$ \\
\hline & DI & $9.6320 \%$ & $7.4872 \%$ & $8.5012 \%$ & $8.1422 \%$ & $8.3883 \%$ & $9.2791 \%$ \\
\hline & PCCE & $9.1047 \%$ & $8.4181 \%$ & $8.4273 \%$ & $7.6383 \%$ & $7.6639 \%$ & $7.6798 \%$ \\
\hline & HA & $0.5855 \%$ & $0.3387 \%$ & $1.6902 \%$ & $0.5445 \%$ & $1.3670 \%$ & $1.8472 \%$ \\
\hline & LS & $1.8978 \%$ & $4.0562 \%$ & $2.5704 \%$ & $1.9402 \%$ & $1.4737 \%$ & $1.5353 \%$ \\
\hline
\end{tabular}

Table 1 shows the average annual growth rate data of various provinces in North China. It can be seen from the table that there are differences in the average annual growth rate of the variables in various provinces, and it can also be concluded that the variables are heterogeneous across provinces.

Table 1. The average annual growth rate of variables in 6 provinces in North China. 


\begin{tabular}{|c|c|c|c|c|c|c|c|}
\hline Rural & $E$ & $7.1848 \%$ & $6.7270 \%$ & $7.9050 \%$ & $7.1229 \%$ & $6.8727 \%$ & $-2.3636 \%$ \\
\hline \multirow[t]{5}{*}{ Panel } & POP & $1.1736 \%$ & $-0.1636 \%$ & $-1.8893 \%$ & $-1.7248 \%$ & $-2.1164 \%$ & $-1.8892 \%$ \\
\hline & DI & $9.2088 \%$ & $8.2234 \%$ & $10.2521 \%$ & $9.1614 \%$ & $10.1244 \%$ & $10.3831 \%$ \\
\hline & PCCE & $9.7131 \%$ & $14.4378 \%$ & $12.4681 \%$ & $10.3722 \%$ & $9.6841 \%$ & $12.0611 \%$ \\
\hline & HA & $1.7235 \%$ & $2.2244 \%$ & $6.9727 \%$ & $3.7295 \%$ & $6.3249 \%$ & $6.5828 \%$ \\
\hline & LS & $1.4699 \%$ & $2.4847 \%$ & $4.0047 \%$ & $3.3511 \%$ & $2.4865 \%$ & $2.6346 \%$ \\
\hline
\end{tabular}

\subsection{Panel unit root test}

Based on the above analysis, this section uses the secondgeneration panel unit root test technology CIPS test to determine the stability of LnE, LnPOP, LnDI, LnPCCE,
LnHA, and LnLS. Table 2 lists the results of two panel unit root tests. The results show that the original data of each variable of the two panels are non-stationary, while the first-order differential is stationary. Therefore, all variables are first-order differentials. On this basis, further analysis of the co-integration relationship between variables.

\begin{tabular}{cccccccc}
\hline CIPS test $^{\text {a }}$ & Variable & LnE & LnPOP & LnDI & LnPCCE & \multicolumn{1}{l}{ LnHA } & LnLS \\
\hline Urban Panel & Level & -2.055 & -2.196 & -2.015 & -2.049 & -1.579 & -1.394 \\
& 1st diff. & $-2.5212^{\mathrm{c}}$ & $-2.590^{\mathrm{b}}$ & $-3.104^{\mathrm{c}}$ & $-2.834^{\mathrm{b}}$ & $-2.740^{\mathrm{b}}$ & $-2.574^{\mathrm{b}}$ \\
\hline Rural Panel & Level & -2.130 & -1.604 & -2.077 & -2.093 & -1.814 & -1.417 \\
& 1 st diff. & $-2.950^{\mathrm{c}}$ & $-2.539^{\mathrm{b}}$ & $-3.369^{\mathrm{c}}$ & $-3.834^{\mathrm{c}}$ & $-2.554^{\mathrm{b}}$ & $-3.051^{\mathrm{c}}$ \\
\hline
\end{tabular}

${ }^{\mathrm{a}}$ CIPS test is estimated using constant and trend with 1 lag.

${ }^{\mathrm{b}}$ Denote the significance level at 5\%.

${ }^{c}$ Denote the significance level at $1 \%$.

\subsection{Panel co-integration test}

The results of the urban and rural panel co-integration test are shown in Table 3. For the urban panel, in the seven test statistics of the Pedroni residual co-integration test, there are long-term equilibrium relationships among five variables. According to Pedroni, it can be considered that there is a long-term equilibrium relationship among LnE,
LnPOP, LnDI, LnPCCE, LnHA, and LnLS. In addition, the Kao co-integration test also confirmed the existence of co-integration relationships between various variables. For the rural panel, there is a long-term equilibrium relationship among the four variables in the Pedroni residual co-integration test, and the Kao co-integration test also confirms the co-integration relationship between the variables. In summary, there is a co-integration relationship between the urban and rural panel variables.

Table 3. Results of panel co-integration test.

\begin{tabular}{|c|c|c|c|c|}
\hline \multicolumn{5}{|c|}{ Pedroni residual co-integration test } \\
\hline \multirow{2}{*}{ Test Statistics } & \multicolumn{2}{|c|}{ Urban Panel } & \multicolumn{2}{|c|}{ Rural Panel } \\
\hline & Value & Probability & Value & Probability \\
\hline Panel v-Statistic & -1.6736 & $0.0952^{\mathrm{a}}$ & -2.2541 & $0.0987^{\mathrm{a}}$ \\
\hline Panel rho-Statistic & 2.3429 & 0.9904 & 3.1362 & 0.9991 \\
\hline Panel PP-Statistic & -4.8354 & $0.0000^{\mathrm{c}}$ & 0.6150 & 0.7307 \\
\hline Panel ADF-Statistic & -2.2736 & $0.0115^{\mathrm{b}}$ & -1.3916 & $0.0347^{\mathrm{b}}$ \\
\hline Group rho-Statistic & 3.1388 & 0.9992 & 3.5965 & 0.9998 \\
\hline Group PP-Statistic & -9.4428 & $0.0000^{\mathrm{c}}$ & -6.0973 & $0.0000^{\mathrm{c}}$ \\
\hline Group ADF-Statistic & -1.6371 & $0.0508^{\mathrm{a}}$ & -2.1611 & $0.0153^{\mathrm{b}}$ \\
\hline \multicolumn{5}{|c|}{ Kao co-integration test } \\
\hline \multirow{3}{*}{$\mathrm{ADF}$} & Urban Pan & & Rural Pane & \\
\hline & t-Statistic & Prob. & $\mathrm{t}-$ Statistic & Prob. \\
\hline & -5.1877 & $0.0000^{\mathrm{c}}$ & -3.8109 & $0.0001^{\mathrm{c}}$ \\
\hline
\end{tabular}

${ }^{\text {a }}$ Denote the significance level at $10 \%$.

${ }^{b}$ Denote the significance level at $5 \%$.

${ }^{\mathrm{c}}$ Denote the significance level at $1 \%$.

\subsection{Panel data model estimation}

In order to avoid being affected by the possible sequence correlation and endogeneity in the panel model, this section uses DOLS and FMOLS methods to estimate the elasticity of E relative to POP, DI, PCCE, HA and LS. The urban and rural panel estimation results are shown in Table 6 respectively. On the whole, based on the two models, the results of each variable in terms of sign and significance are similar, but slightly different in magnitude.

In the urban panel, the results of the DOLS model show that POP, DI, PCCE, HA and LS increase by $1 \%$, and $E$ will increase by $0.24 \%, 1.11 \%, 0.94 \%, 0.34 \%$ and $0.32 \%$ respectively. The results of the FMOLS model show that when POP, DI, PCCE, HA and LS increase by $1 \%$, E will increase by $0.29 \%, 1.05 \%, 0.92 \%, 0.34 \%$ and 
$0.30 \%$, respectively. In the rural panel, the results of the DOLS model show that POP, DI, PCCE, HA and LS will increase by $1 \%$, and $\mathrm{E}$ will increase by $0.32 \%, 1.47 \%$, $0.88 \%, 0.21 \%$ and $0.19 \%$ respectively. The results of the FMOLS model show that when POP, DI, PCCE, HA and LS increase by $1 \%$, E will increase by $0.39 \%, 1.13 \%$, $0.86 \%, 0.20 \%$ and $0.18 \%$, respectively.
The results of DOLS and FMOLS show that with the increase in population, the improvement of living standards and the improvement of living conditions, the electricity consumption of urban and rural residents in North China will show an increasing trend.

Table 4. Estimation results of DOLS and FMOLS models for panel (Dependent variable: LnE).

\begin{tabular}{|c|c|c|c|c|c|}
\hline & \multirow{2}{*}{ Variable } & \multicolumn{2}{|c|}{ DOLS } & \multicolumn{2}{|c|}{ FMOLS } \\
\hline & & Coefficient & t-Statistic & Coefficient & t-Statistic \\
\hline \multirow[t]{6}{*}{ Urban Panel } & LnPOP & 0.2399 & $2.2637^{\mathrm{b}}$ & 0.2871 & $1.7811^{\mathrm{a}}$ \\
\hline & LnDI & 1.1149 & $4.0663^{\mathrm{c}}$ & 1.0474 & $4.1220^{c}$ \\
\hline & LnPCCE & 0.9418 & $2.1109^{b}$ & 0.9203 & $2.1875^{\mathrm{b}}$ \\
\hline & LnHA & 0.3385 & $2.0225^{\mathrm{b}}$ & 0.3427 & $1.9028^{a}$ \\
\hline & LnLS & 0.3183 & $1.8227^{\mathrm{a}}$ & 0.2984 & $1.9866^{\mathrm{b}}$ \\
\hline & R-squared & \multicolumn{2}{|c|}{0.981447} & \multicolumn{2}{|c|}{0.982720} \\
\hline \multirow[t]{6}{*}{ Rural Panel } & LnPOP & 0.4204 & $1.9964^{\mathrm{a}}$ & 0.4900 & $2.1468^{b}$ \\
\hline & LnDI & 1.4705 & $4.0305^{\mathrm{c}}$ & 1.1317 & $4.1296^{\mathrm{c}}$ \\
\hline & LnPCCE & 0.8784 & $2.3286^{\mathrm{b}}$ & 0.8569 & $2.0521^{\mathrm{b}}$ \\
\hline & LnHA & 0.2100 & $2.0221^{\mathrm{b}}$ & 0.2014 & $2.2712^{\mathrm{b}}$ \\
\hline & LnLS & 0.1900 & $2.3085^{\mathrm{b}}$ & 0.1844 & $2.0554^{\mathrm{b}}$ \\
\hline & R-squared & \multicolumn{2}{|c|}{0.975865} & \multicolumn{2}{|c|}{0.981673} \\
\hline
\end{tabular}

${ }^{a}$ Denote the significance level at $10 \%$.

${ }^{\mathrm{b}}$ Denote the significance level at $5 \%$.

${ }^{\mathrm{c}}$ Denote the significance level at $1 \%$.

\section{Conclusions}

This paper divides residential electricity consumption into two panels. Based on the data of North China from 2008 to 2018 , the heterogeneous panel analysis techniques are applied to examine the influencing factors such as population size, residential income and expenditure levels, and household characteristics on electricity consumption of residents.

The empirical results indicate that in both urban and rural panels, residential income is the most important factor influencing residential electricity consumption, followed by consumption expenditure. The role of residential income in promoting electricity consumption of rural residents is greater than that of urban residents, and the role of consumption expenditure in promoting electricity consumption of urban residents is greater than that of rural residents. In addition, the number of household appliances and the per-capita housing area, both have significant positive impacts on the electricity consumption of residents, and their promotion on electricity consumption of urban residents is greater than that of rural residents.

Based on empirical findings, increasing residential income and changing residential consumption habits to promote residential consumption expenditure are key ways to increase residential electricity consumption. Meanwhile, policies such as subsidies for the purchase of household appliances can be implemented to promote the increase in the number of household appliances, thereby increasing household electricity consumption. While increasing the electricity consumption of residents, attention should be paid to increasing the income of rural residents, and to narrow the gap between urban and rural residential electricity consumption, which can promote the balanced development of regional urban and rural areas to facilitate the coordinated planning of urban and rural energy policies.

\section{ACKNOWLEDGMENTS}

This research was funded by the project "Research on the impact of the tertiary industry and residential electricity demand" of the State Grid North China Branch Project (SGTYHT/19-JS-218). This research was funded by National Natural Science Foundation of China, grant number 71973043.

\section{References}

1. X. Zhao, Z. Yuan, J. Ma, et al. An Evaluation and Analysis on the Performance of the Policy Coordination Modes in Air Pollution Prevention and Control in the Jingjinji Metropolitan Region and an Exploration of its Future Schema. Chinese Public Adm, (2019)

2. Z. Guo, K. Zhou, C. Zhang, et al. Residential electricity consumption behaviours: Influencing factors, related theories and intervention strategies. Renew. Sust. Energ. Rev. 81: 399-412 (2018)

3. Y. Wang, H. Lin, Y. Liu, et al. Management of household electricity consumption under price-based demand response scheme. J. Clean. Prod. 204: 926938 (2018)

4. S. Zhang, B. Lin. Impact of tiered pricing system on China's urban residential electricity consumption: 
Survey evidences from 14 cities in Guangxi Province.

J. Clean. Prod., 170: 1404-1412 (2018)

5. M. Frondel, S. Sommer, C. Vance. Heterogeneity in German Residential Electricity Consumption: A quantile regression approach. Energy Policy. 131: 370-379 (2019)

6. K. Chen, J. Jiang, F. Zheng, et al. A novel data-driven approach for residential electricity consumption prediction based on ensemble learning. Energy.150: 49-60 (2018) 